NASA TECHNICAL

MEMORANDUM
N. 26281

NASA TM X-52785

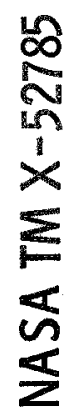

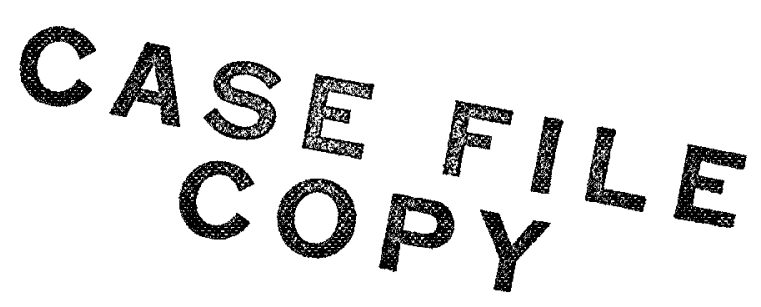

\title{
LARGE SCALE SUPERSONIC COMBUSTOR TESTING AT CONDITIONS SIMULATING MACH 8 FLIGHT
}

by A. J. Metzler and T. W. Mertz

Lewis Research Center

Cleveland, Ohio

TECHNICAL PAPER proposed for presentation at Sixth Propulsion Joint Specialist Conference sponsored by the American Institute of Aeronautics and Astronautics San Diego, California, June 15-19, 1970 
LARGE SCALE SUPERSONIC COMBUSTOR TESTING A T CONDITIONS SIMULATING MACH 8 FLIGHT

by A. J. Metzler and T. W. Mertz

Lewis Research Center

Cleveland, Ohio

TECHNICAL PAPER proposed for presentation at

Sixth Propulsion Joint Specialist Conference sponsored by the American Institute of Aeronautics and Astronautics San Diego, California, June 15-19, 1970 


\title{
LARGE SCALE SUPERSONIC COMBUSTOR TESTING AT CONDITIONS SIMULATING MACH 8 FLIGHT
}

\author{
A. J. Metzler and T. W. Mertz \\ Lewis Research Center \\ National Aeronautics and Space Administration \\ Cleveland, Ohio
}

\section{Abstract}

A hydrogen fueled supersonic-burning combustor 18-in. in diameter, which is equivalent to that of an engine about 6-ft in diameter, was tested as a directconnected duct at inlet conditions which simulated Mach 8 flight at $115,000 \mathrm{ft}$ altitude. A synthetic air consisting of oxygen with $39 \%$ nitrogen and $38 \%$ water vapor at a total temperature of $4500^{\circ} \mathrm{R}$ and a total pressure of 300 psia was supplied to the combustor inlet by a hydrazine-nitrogen tetroxide hot gas generator which maintained a uniform inlet flow Mach number of 2.8. The large combustor size required a new approach to fuel injector design. Some hydrogen was injected through flush-wall injectors, but most was injected from two rows of swept and tapered struts immersed in the flow stream. Supersonic combustion was obtained at hydrogen equivalence ratios of 0.94 without encountering thermal choking. Wall static pressures, and the radial distribution of hydrogen, pitot pressure, and Mach number were determined at the combustor exit.

\section{Introduction}

Supersonic burning combustors proposed for hypersonic airbreathing vehicles operate at very high levels of stagnation temperature and pressure at the combustor inlet. In ground test facilities it becomes extremely difficult, therefore, to reproduce the inlet conditions a combustor would experience during hypersonic flight. As a result, testing of supersonic burning combustors for hypersonic application has generally been subject to compromise. Testing has been largely restricted to short-duration or pulse-type testing, or to very small-scale combustors in order to ease the facility air supply requirements. Unfortunately, the results of such testing cannot be scaled to permit the prediction of the performance of large combustors which would ultimately be required for a vehicle application. Large combustors will require a fuel injection geometry radically different from the wall injection schemes used in small scale combustors which cannot reflect the injection-mixing-combustion interactions which would occur in a large combustor. Therefore, although the results of prior combustor testing may predict parametric trends of large-scale combustor performance, direct scaling of the results is not possible. In fact, the practicality of the concept of a supersonic burning combustor for complex, fullscale hardware has not been previously demonstrated.

The purpose of the large-scale combustor test program reported herein was two-fold. The use of a hot ga.s generator ${ }^{1}$ for large scale supersonic combustor testing was to be demonstrated. Secondly, supersonic combustion was to be demonstrated in large scale hardware of a practical geometry at a single set of combustor inlet conditions and to obtain, if possible, a preliminary estimate of combustor performance.

The test conditions simulated a vehicle flight at Mach 8 at an altitude of $115,000 \mathrm{ft}$. Since combustor studies of this type were without precedent, it was also intended to define some of the problem areas which would be pertinent to future, more detailed studies.

A supersonic combustor was tested as a directconnected duct using a hydrazine-nitrogen tetroxide rocket as the combustor inlet-gas generator. The gas generator duplicated the combustor inlet temperature, pressure, and Mach number for Mach 8 altitude flight, but the gas composition did not duplicate that of clean air since the inerts consisted of $39 \mathrm{vol} . \%$ of nitrogen and 38 vol.\% of water vapor. Gas generator and combustor hardware were water cooled. The combustor had an inlet i.d. of 18 -in. $(45.7-\mathrm{cm})$ which might be equivalent to that of an engine about $2 \mathrm{~m}$ in diameter. The combustor was fueled with gaseous hydrogen at ambient temperature.

This paper reports the results of testing this combustor at a single set of inlet conditions. Data were obtained with one basic hydrogen injector geometry for hydrogen equivalence ratios from 0 to 0.94 . For most tests reported burn time was $15 \mathrm{sec}$ and all data were taken during steady state conditions. These preliminary results do not include measurements of thrust or efficiency of the chemical conversion process. The effects of vitiation on the test results are not known. The demonstration of super sonic burning in a large size combustor having a practical hydrogen injector geometry, however, is new and significant to the development of large, hypersonic flight vehicles.

This combustor test program was performed in an altitude test chamber at the Lewis Research Center, Cleveland, Ohio.

\section{Facility and Test Hardware}

The combustor test facility is shown schematically in Figure 1 as it was installed in the altitude tank. The gas generator with contoured nozzle and test combustor were assembled as a direct-connect duct exhausting as a free jet into the altitude chamber which was pumped to about one-fifth atm. The combustor exhaust was collected by a diffuser prior to entering the vacuum 
piping. All hardware was water cooled.

Gas generator. - The gas generator was a rocket combustor which burned the hypergolic propellants hydrazine-nitrogen tetroxide. The rocket injector was developed specifically for stable, high performance at 300 psia $\left(2.06 \times 10^{6} \mathrm{~N} / \mathrm{m}^{2}\right)$ chamber pressure at an oxidant-fuel ratio $(\mathrm{O} / \mathrm{F})$ equal to 3.0. Preliminary injector tests ${ }^{1}$ had indicated problems with the development of a gas generator of this type since combustion was frequently unstable and could cause gas generator damage. A specific like-on-like parallel-fan injector design $^{2}$ demonstrated very stable performance at design conditions together with a high characteristic velocity $\left(C^{*}\right)$. efficiency. $C^{*}$ efficiency was 97 to $98 \%$ which is equivalent to a combustion efficiency of 94 to $96 \%$. Stable runs of $20 \mathrm{sec}$ duration were attained, and longer run time with no injector damage would have been possible.

The combustion chamber had an i.d. of $10.78 \mathrm{in.}$ $(27.4 \mathrm{~cm})$ and a characteristic length $\left(\mathrm{I}^{*}\right)$ of 38 for a nominal chamber length of $20 \mathrm{in.}(50.8 \mathrm{~cm})$. The likeon-like parallel-fan design had 360 elements drilled into the injector face. At design conditions, propellant mass flow was $99 \mathrm{lb}(44.9 \mathrm{~kg}$ ) per second. Run time for this phase of the program was restricted to $15 \mathrm{sec}$ but is practically limited to $100 \mathrm{sec}$ by the total oxidant storage capacity available. High frequency response pressure instrumentation verified that stable combustion performance was obtained. No injector deterioration was noted after a total run time of $5 \mathrm{~min}$ which included 32 separate ignition sequences.

The inlet nozzle was contoured for parallel flow and Mach 2.8 at the $18-$ in. $(45.7-\mathrm{cm})$ diameter exit. The nozzle contour was designed according to the real gas method of characteristics which used a starting line determined by Sauer's method. ${ }^{3}$ The inviscid contour was corrected by the boundary layer displacement thickness calculated by the method of Reshotko and Tucker. ${ }^{4}$ The contoured nozzle was a machined and welded aluminum forging. Instrumentation measured the flow rates, temperatures, and pressures necessary to calculate gas generator performance, to monitor coolant system operation and measure heat loss, and to evaluate the nozzle exit flow.

Combustor test hardware. - The combustor consisted of the hydrogen injector struts and three duct sections which are pictured in Figure 2. The sequence of assembly is from left to right with the inlet to each section located at the top of the figure. The combustor consisted of a constant area inlet and injection section (left), a wall injection ring (center), and an expansion section (right). The injection and expansion sections were fabricated as double wall structures for water cooling; the injection ring was hydrogen cooled. Features of the assembly of the combustor section are detailed in Figure 3. The combustor inlet section was a nickel cylinder 18 in. $(45.7 \mathrm{~cm})$ i.d. by $25 \mathrm{in} .(63.5 \mathrm{~cm})$ long. Mounting plates for 16 hydrogen injection struts were equally spaced at two axial locations as shown in the figure. The wall-injection ring was $1.3 \mathrm{in} .(3.3 \mathrm{~cm})$ wide with an i.d. of $18.38 \mathrm{in} .(46.7 \mathrm{~cm})$ which matched that of the expansion section inlet. A circumferential step $0.188 \mathrm{in} .(0.478 \mathrm{~cm})$ high was thus formed with the cylindrical inlet section. In the wake of this step, hydrogen was injected through 72 equally-spaced holes 0.1695 in. $(0.4305 \mathrm{~cm})$ in diameter. The ring was cooled by the injected hydrogen flow. The inner shell of the conical expansion section of the combustor was mild steel flame-spray coated with zirconium oxide. The cone inlet i.d. was 18.38 in. $(46.7 \mathrm{~cm})$, and the expansion half angle was $2^{\circ}$.

The hydrogen injector struts were designed to penetrate the inlet flow stream with minimum flow disturbance and blockage and to distribute the hydrogen across the stream as uniformly as possible. The injectors were single nickel shells cooled by the injected hydrogen. The struts swept rearward at $30^{\circ}$ (Fig. 3) and had a diamond shaped cross section aligned with the flow stream. Sonic flow injection orifices were drilled at the knee of the diamond and at the trailing edge. The injection orifices were 0,141 and $0.156 \mathrm{in.}(0,358$ and $0.396 \mathrm{~cm}$ ) in diameter. The internal flow of the injected gaseous hydrogen cooled the struts, and initially the only provision that was made to adjust the coolant flow to the nonuniform heat flux was to deflect the incoming gas toward the leading edge of the injector. A simple plate inclined at $67^{\circ}$ to the hydrogen flow direction at the injector inlet was used for this purpose. This cooling method proved inadequate and required subsequent modification. In the modified injector struts, the leading edge was cooled with a separate hydrogen coolant tube, 0.125 -in. $(0.317-\mathrm{cm})$ with a $0.020-$ in. $(0.051-\mathrm{cm})$ wall, which formed the strut leading edge. The internal hydrogen flow cooled the lateral, lower heat-flux areas of the injector strut.

Four injector struts penetrated the stream 7 in. $(17.8 \mathrm{~cm})$ from the inner combustor wall, and four penetrated $6.25 \mathrm{in}$. $(15.8 \mathrm{~cm})$. These were located in the first row as shown in Figure 3 . Second row injectors all penetrated the stream 4.10 in. $(10.4 \mathrm{~cm})$.

One injector in each row was specially instrumented to measure internal hydrogen pressure and pressure drop, surface temperatures, and surface static pressure. A pitot tube was installed on the leading edge of one first row strut (Fig. 4).

Each combustor section had wall static pressure taps which extended the length of the combustor at two circumferential positions. As shown in Figure 5, one series of taps was in line with a first row injector strut and the other was aligned between the first and second row strut positions. Wall thermocouples were similarly positioned, but in the cylindrical section only, to monitor gas-side and coolant-side wall temperatures. Figure 5 also shows the relative positioning of the pressure tap in the hydrogen injector ring.

Fixed rake and traversing probe instrumentation was used to measure the gas stream total and static 
pressures. Total temperatures and gas samples were obtained from fixed rakes mounted across the exit stream diameter. Stream temperatures were measured in such rakes with radiation cooled Iridium versus Iridium- $40 \%$ Rhodium thermocouples. The thermocouples were replaceable elements in a rake which could also be used to measure pitot pressure or to obtain gas samples from the flow stream.

A traversing pitot probe and support strut are shown in Figure 6. The probe and strut were built according to the design of the high-enthalpy instrumentation described in Reference 5. The strut was flame-spray coated with zirconium oxide for additional thermal protection and was sharp edged. During the first run, the edge of the strut melted back to an approximate 0.060 -in. $(0.154-\mathrm{cm})$ radius, but no additional melt-back of the coated blunt edge occurred in following runs. (The copper pitot probe tip blunted to a $0.005-\mathrm{in} .(0.012-\mathrm{cm})$ radius at the same stream conditions.) The probe traversed up to $10-\mathrm{in} .(25.4-\mathrm{cm})$ across the flow stream, and, together with the strut, was cooled with high pressure water.

\section{Combustor Inlet Conditions}

Mach 8 flight at $115,000 \mathrm{ft}(35 \mathrm{~km})$ altitude and a diffuser pressure recovery of $20 \%$ were assumed to define the conditions at the inlet plane of the combustor. For design purposes, the inlet Mach number was further assumed to be 2.8. These conditions then defined the gas generator operating parameters and the nozzle contour.

Combustor inlet conditions were measured at the exit of the contoured nozzle and were assumed to be unchanged after the combustor hardware was installed. Subsequent measurement of wall static pressure in the combustor verified the validity of this assumption. Nozzle exit static pressure was measured slightly upstream of the exit plane and was extrapolated to an exit value. Pitot pressure and stream total temperature were measured 3 to $5 \mathrm{in}$. $(7.6$ to $12.7 \mathrm{~cm})$ downstream of the nozzle exit plane in the region of parallel flow and were assumed to be constant for this distance.

The exit profiles are plotted in Figure 7. Pitot pressure as measured by the traversing probe (Fig. 6) and as measured by a fixed multi-point rake are compared in the figure. Rake measurements were consistently lower than those with the probe, but the probe pitot measurements are considered to be more valid than tho se obtained with the fixed rake because of the large shock-detachment distance for the blunt-nosed rake. However, the rake measurements did indicate the flatness of the momentum profile across the stream diameter. The flow Mach number was calculated from the pitot pressures plotted in Figure 7 (a) assuming a stream static pressure equal to the extraploated nozzle exit wall static pressure of 8.3 psia $\left(5.57 \times 10^{4} \mathrm{~N} / \mathrm{m}^{2}\right)$. Gamma was assumed equal to 1.27 which is the value computed according to Reference 6 for a kinetic nozzle expansion. Close agreement with the nozzle design Mach number of 2.8 as well as the flat flow profile of the combustor inlet-stream are apparent from the figure.

Combu stor inlet total temperature was measured directly with a fixed multi-point rake of radiation cooled thermocouples. The measured temperature profile of the stream, corrected for radiation loss, is plotted in Figure 7 (c) as a function of stream diameter. Duplicate runs reproduced indicated gas temperatures, uncorrected for radiation, within $\pm 4 \%$ and included the reproducibility of the propellant control system and combustion process as well as the sensitivity of the measurement to the installation of the individual thermocouple in the rake structure. The accuracy of the temperatures reported is estimated to be $\pm 5 \%$. All measured temperatures were corrected for radiation loss. The correction was approximately $100^{\circ}$ to $185^{\circ} \mathrm{R}\left(54^{\circ}\right.$ to $\left.102^{\circ} \mathrm{K}\right)$ for the data reported with an assumed temperature dependent emissivity of 0.163 to 0.211 . The $4450^{\circ} \mathrm{R}\left(2470^{\circ} \mathrm{K}\right)$ temperature level indicated for the bulk of the flow stream is in good agreement with the temperature of $4530^{\circ} \mathrm{R}$ $\left(2520^{\circ} \mathrm{K}\right)$ estimated from the theoretical reaction temperature corrected to the measured rocket $\mathrm{C}^{*}$ efficiency but neglecting the heat loss to the nozzle coolant.

The combustor inlet conditions are summarized in Table 1 and compared to the conditions theoretically attainable with a hydrazine-nitrogen tetroxide gas generator. Inlet conditions for Mach 8 flight are also shown in the table for comparison. It is apparent that reasonably good simulation of combustor inlet conditions for flight was obtained with the gas generator, but flow profiles of the Mach number and temperature measured at the combustor inlet were probably flatter than would be delivered by an inlet of a flight vehicle.

The measured gas composition reported in the table is representative only of the molecular levels of the three constituents at the combustor inlet and reports nitric oxides as equivalent nitrogen and oxygen concentrations. However, the measured gas generator $\mathrm{C}^{*}$ efficiency of 97 to $98 \%$ would be indicative of a gas composition consistent with that predicted by theory.

\section{Supersonic Combustor Tests}

Basic test procedure. - There was no precedent for testing a supersonic burning combustor of either an equivalent size or geometry at the conditions specified for this experimental program. Consequently, a rather cautious and incremental approach to the attainment of the test goals was planned. The combustor was designed to operate with a full set of sixteen hydrogen injector struts as well as hydrogen injection from the wall at a single axial station. This full configuration was approached in a step-wise manner in order to obtain the maximum information with a minimum risk to the test hardware. Combustor wall heat transfer rates were first obtained from tests with an empty duct and were followed by testing injector struts in the increasing numbers of $1,4,8$, and 16 . Hydrogen injection rate 
was similarly increased progressively. For any test, minimum hydrogen flow rates were governed by the injector cooling requirements determined experimentally. The maximum hydrogen flow rate for an equivalence ratio of 1.0 was $3.2 \mathrm{pps}(1.45 \mathrm{~kg} / \mathrm{sec})$.

Combustor wall heat transfer. - The inner wall of the cylindrical combustor section was $3 / 16-i n$. thick Nickel 200 and was instrumented at selected locations (Fig. 5) to measure gas-side and coolant-side wall temperatures. With no burning, the wall heat transfer rate was approximately $0.8 \mathrm{Btu} / \mathrm{sec}-\mathrm{in} .{ }^{2}\left(1.3 \times 10^{6} \mathrm{watt} / \mathrm{m}^{2}\right)$ and gas-side heat transfer coefficients ranged from 200 to $240 \times 10^{-6} \mathrm{Btu} / \mathrm{in} .^{2}-\mathrm{sec}-{ }^{0} \mathrm{~F}$ (590 to $\left.700 \mathrm{watts} / \mathrm{m}^{2}{ }^{0} \mathrm{~K}\right)$. Limited data with combustion indicated no major increase in heat transfer in the cylindrical section, but pressure measurements detected little, if any, combustion in this region. Wall heat transfer in the expansion section was not determined.

Hydrogen injector cooling. - The basic hydrogen injector strut design incorporated a simple baffle plate at the hydrogen inlet to deflect the high velocity flow stream toward the leading edge of the strut. This system was proposed to force-cool the high heat flux leading edge region of the injector. It became evident very early in the test program, however, that this system was inadequate to cool the leading edge at the design hydrogen flow rates. Measurement of the leading edge temperature near the injector tip indicated dangerously high temperatures were reached in very short periods of time. Leading edge surface temperatures near $2600^{\circ} \mathrm{R}\left(1445^{\circ} \mathrm{K}\right)$ were recorded after only $14 \mathrm{sec}$ of operation with a strut hydrogen flow rate of $0.25 \mathrm{pps}$ which was $25 \%$ greater than the design flow rate. After $15 \mathrm{sec}$ total operation, some injector damage occurred at the leading edge; this is illustrated in Figure 8 . In most cases, the leading edge melted and the injector split open near the strut tip. Lower hydrogen flow rates accentuated the problem.

A modification to the basic injector design was tested. The injector leading edge was replaced with a nickel tube of equal radius which was brazed into the structure. A separate high pressure hydrogen supply cooled the tube and vented to the stream at the end of the injector. Although no injector surface temperatures were measured with this configuration, inspection indicated no leading edge damage even with injection flow rates $25 \%$ lower than required for stoichiometric burning. Even further flow reduction is believed possible without causing injector leading edge overheating. However, the vented hydrogen burned along the strut closure plate, and erosion was noted after several tests; such damage is shown in Figure 9. Subsequent design will either return the flow to the strut interior or will vent the hydrogen at the trailing edge.

Hydrogen distribution. - The gas stream was sampled at several points across the combustor exit, and the analyses were converted to local hydrogen equivalence ratio. The results are summarized in Figure 10 as a function of combustor radius for samples taken only in the wake of long, first row injector struts. Also indicated on the figure are the radial locations of . the individual injector ports.

Limited data with hydrogen injected only from the wall injection ring indicated that the hydrogen penetrated and spread only a short distance into the stream and remained close to the wall. Measured equivalence ratios reached 2.2 for hydrogen injection rates of $0.8 \mathrm{lb} / \mathrm{sec}$ $(0.36 \mathrm{~kg} / \mathrm{sec})$. Concentration measurements at points further from the wall were not made, but it is apparent that the hydrogen concentration must rapidly fall to zero a short distance from the wall.

The lower curve of the figure describes most of the data obtained and includes data of several injector configurations ranging from only a single long strut to a complete complement of 16 struts. For these data hydrogen flow rates ranged from 0.15 to $0.25 \mathrm{lb} / \mathrm{sec}$ $(0.07$ to $0.11 \mathrm{~kg} / \mathrm{sec})$ per long injector strut. For comparison, the hydrogen flow rate would approach $0.2 \mathrm{lb} /$ sec $(0.091 \mathrm{~kg} / \mathrm{sec})$ per strut with a full configuration of 16 injector struts operating at stoichiometric. For all configurations represented by the curve, peak equivalence ratios only slightly greater than stoichiometric were measured and the curve was rather flat. Wall injection rates ranged from 0.2 to $0.4 \mathrm{lb} / \mathrm{sec}(0.09$ to $0.18 \mathrm{~kg} / \mathrm{sec}$ ). To show the effect of an increased hydrogen injector flow rate on the hydrogen distribution, one test was made with an injector configuration of 4 long struts. The effect of the increased hydrogen rate is markedly shown by the upper curve. Fuel rich mixtures were measured over almost the entire survey.

For these data, equivalence ratio was computed from an analysis of the dry gas sample and assumed a water concentration based upon a theoretical molecular balance at the combustor inlet. Therefore the absolute values of the equivalence ratios reported are approximate. The general distribution level and patterns, however, are believed to be realistic.

Combustor test results. - Combustor data were obtained with a full complement of 16 hydrogen injector struts, 8 in each of the two rows, and the stepped-wall injection ring. Hydrogen flow was staged between the three axial injection stations. Flow rates were 2.0 and $0.9 \mathrm{lb} / \mathrm{sec}(0.9$ and $0.4 \mathrm{~kg} / \mathrm{sec})$ in rows 1 and 2 , respectively, and $0.2 \mathrm{lb} / \mathrm{sec}(0.09 \mathrm{~kg} / \mathrm{sec})$ was injected from the wall. The overall combustor equivalence ratio was 0.94 .

The measured stream static and pitot pressures and the calculated Mach number profile are plotted in Figure 11 as a function of the combustor exit radius. The data reported were obtained in a plane approximately 6-in. (15.2-cm) downstream of the combustor exit, where the duct area was $22 \%$ greater than the combustor exit. The instrumentation flange formed a $0.85-$ in. 
$(2.16 \mathrm{~cm})$ rearward-facing step with the combustor exit. An expansion fan was, thus, introduced into the flow stream at this point, and propagation of the expansion waves into the stream influenced pressure measurements some distance out from the stream boundary. Data are reported, therefore, only to stream radii less than 7 -in. $(17.7-\mathrm{cm})$ as measured from the center line to minimize the influence of the expansion on the stream measurements.

Figure 11 shows that pitot pressures ranged from 40 to $102 \mathrm{psia}\left(2.4\right.$ to $\left.7.0 \times 10^{5} \mathrm{~N} / \mathrm{m}^{2}\right)$ over the stream radius surveyed. Stream static pressures were measured only over a $3-$ in. $(12.7-\mathrm{cm})$ traverse and indicated a static pressure level of $14 \mathrm{psia}\left(9.6 \times 10^{4} \mathrm{~N} / \mathrm{m}^{2}\right)$. The probe failed before more data could be obtained.

The Mach number profile plotted in Figure 11(c) was calculated from the measured pitot pressure and assumed the stream static pressure to be 14 psia $\left(9.6 \times 10^{4} \mathrm{~N} / \mathrm{m}^{2}\right)$ over the stream cross section. Calculated Mach numbers ranged from 2.4 to 1.5 with the higher values occurring near the stream center line where prior data had indicated low fuel concentration. The Mach number was calculated from the Rayleigh pitot relation and assumed a value for gamma of 1.22 . The sensitivity of Mach number to the value of gamma, however, is low so the Mach numbers calculated are probably less in error from the gamma inaccuracy than from inaccuracies in the measurement of stream pressures.

Combustor wall static pressures were measured along two axial positions which extended the length of the combustor and which were separated by a radial arc of approximately $34^{\circ}$ (Fig. 5). Therefore, a flow disturbance or shock wave originating from a point such as the leading edge of an injector would be detected at a different axial position in each row of pressure instrumentation depending on the relative location of the source of the disturbance and the angle of propagation. Except for such instances, the wall static pressures measured by the two different rows of instrumentation agreed within the experimental error.

Combustor wall static pressures are plotted in Figure 12 as a function of combustor length for three different configurations. The pressure distribution for the empty duct is plotted to indicate the base line pressure distribution for the combustor inlet flow conditions. The pressures reported are normalized with the combustor inlet pressure, $\mathrm{P}_{\mathrm{T} 2}$, and are reported as the pressure ratio $\mathrm{p}_{\mathrm{S}} / \mathrm{P}_{\mathrm{T} 2}$. Base line pressure ratios ranged from 0.028 to 0.018 from combustor inlet to exit, respectively. The effect of the oblique shock system which originated from the first row injectors is apparent in the data shown for 8 injectors with no hydrogen flow. The pressure peaks indicated are local, shock-system conditions and are not representative of the average circumferential pressure level at this axial location. The average circumferential pressure level would be represented by the level of the base line pressure data.
The static pressure rise which resulted from combustion at an equivalence ratio of 0.94 is shown by the upper curve of the figure. The peak pressure ratio of 0.10 occurred $30-\mathrm{in} .(76.2-\mathrm{cm})$ from the combustor inlet and about 4 in. $(10.1 \mathrm{~cm})$ into the $2^{\circ}$ combustor expansion cone. The peak pressure corresponded to a static pressure about 3.6 times as great as the combustor inlet pressure. The shape of the combustor pressure profile was similar to data reported for smaller scale combustors which utilized wall injection for hydrogen. Data were also obtained with incomplete injector configurations. These data are not shown, but the pressure levels measured were correspondingly lower. As is evident from Figure 12, no choking of either aerodynamic or thermal origin occurs in the duct, and the flow remains supersonic. It should especially be noted that even though the maximum local geometric blockage is $4.75 \%$, the pressure rise due to the strut blockage is negligible. The pressure rise due to second row blockage effects was not determined but could be greater than noted for the first row injectors. This would be especially true if combustion of the first row hydrogen resulted in boundary layer separation in the region of the second row injectors.

An attempt was made to estimate the combustor performance from the measurement of the exit Mach number and exit static pressure using a real gas combustor analysis. ${ }^{7}$ However, the calculations indicated that the measured quantities were insensitive to combustor performance and could not be meaningfully applied. Combustor performance can best be obtained by direct measurement of thrust of a combustor-nozzle system.

\section{Concluding Remarks}

The significance of this research program, in light of the present status of supersonic combustor technology, is in the size of the combustor tested and in the uniqueness of the facility developed to test it. For the first time supersonic burning was demonstrated in a large combustor which used hydrogen injectors which were immersed into the flow stream and so indicated that supersonic combustor size and design need not be limited. to the concept of wall injection. Large combustors with practical injector systems can be realities. The combustor tested in this program had an inlet diameter of 18-in. and used sixteen swept injector struts which penetrated the flow stream up to 78 percent of the combustor radius. Combustion to equivalence ratios near stoichiometric was supersonic and no choking occurred. Secondly, a new type of combustor test facility which used a rocket as a hot gas generator was demonstrated. Supersonic combustor inlet conditions simulating altitude flight at Mach 8 were clo sely simulated with the exhaust of the gas generator which burned storable propellants to generate vitiated high enthalpy air. For these tests one basic combustor geometry was designed after consideration of gas dynamics, chemical kinetics, and penetration and mixing criteria. This combustor design was not optimized and the test results indicate required changes for future steady-state combustor testing. Improved injector cooling is necessary, especially if hot 
hydrogen is to be considered for future application. Improved penetration of the hydrogen injected from the wall is also desirable to avoid over-rich regions along the combustor wall. Also, it will be necessary in future tests to measure the combustor thrust in order to determine the combustor performance or combustor efficiency since profiles of stream properties measured by conventional instrumentation are too insensitive to combustor performance.

\section{$\underline{\text { References }}$}

1. Metzler, A. J. and Lezberg, E. A., "A. Hot Gas Generator for Large Scale Supersonic Combustor Testing, " paper 68-647, June 1968, ALAA, New York, N. Y.

2. Wanhainen, J. P. and Vincent, D. W., "Stability and Performance Characteristics of Several Hydrazine and Nitrogen Tetroxide Hot Gas Generators for Large Scale Supersonic Combustor Testing, " TM X-1845, 1969, NASA, Cleveland, Ohio.

3. Sauer, R., "General Characteristics of the Flow Through Nozzles at Near-Critical Speeds," TM 1147,1947 , NACA, Washington, D.C.
4. Reshotko, E. and Tucker, M., "Approximate Calculation of the Compressible Turbulent Boundary Layer With Heat Transfer and Arbitrary Pressure Gradient," TN 4154, 1957, NACA, Cleveland, Ohio.

5. Parobek, D. M., "Performance of Free Stream Flow Instrumentation for 9-Inch Contoured Nozzle Test in the RTD 4-Megawatt Electro Gasdynamic Facility," AFFDL-TR-65-179, DDC No. AD-476608L, Dec. 1965, AF Flight Dynamics Lab., Wright Patterson AFB, Ohio.

6. Moretti, L., "A New Technique for the Numerical Analysis of Non-Equilibrium Flows, "TR-412, DDC No. AD-466922, Mar. 1964, General Applied Science Labs., Inc.; Westbury, N. Y.

7. Franciscus, L. C. and Healy, J. A., "Computer Program for Determining Effects of Chemical Kinetics on Exhaust-Nozzle Performance," TN D-4144, 1967, NASA, Cleveland, Ohio

TABLE 1 COMPARISON OF COMBUSTOR INLET

CONDITIONS FOR THEORY, FLIGHT, AND TEST

\begin{tabular}{|c|c|c|c|}
\hline \multicolumn{4}{|c|}{ Combustor Inlet Conditions } \\
\hline & \multicolumn{2}{|c|}{$\begin{array}{c}\mathrm{N}_{2} \mathrm{H}_{4}-\mathrm{N}_{2} \mathrm{O}_{4} \text { at } \\
\mathrm{O} / \mathrm{F}=3.0\end{array}$} & \multirow[t]{2}{*}{$\begin{array}{c}\text { Mach } 8 \text { Flight } \\
115,000 \mathrm{ft}\end{array}$} \\
\hline & $\begin{array}{c}\text { Kinetic } \\
\text { expansion }\end{array}$ & Measured & \\
\hline $\mathrm{T}$ total ${ }^{\circ} \mathrm{R}$ & 4824 & 4446 & 5022 \\
\hline$T$ static ${ }^{\circ} R$ & 2475 & 2151 & 2227 \\
\hline P total psia & 300 & 300 & 287 \\
\hline P static psia & 8.58 & 8.22 & 8.58 \\
\hline$\gamma$ & 1.268 & 1.26 & 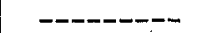 \\
\hline Mach No. & 2.870 & 2.87 & 2.87 \\
\hline Mole fraction $-\mathrm{N}_{2}$ & .3974 & .390 & .7808 \\
\hline$-\mathrm{O}_{2}$ & .2103 & .228 & .2095 \\
\hline$-\mathrm{H}_{2}^{2} \mathrm{O}$ & .3864 & .382 & --n-n- \\
\hline$-\mathrm{OH}$ & .0040 & ----- & - \\
\hline
\end{tabular}




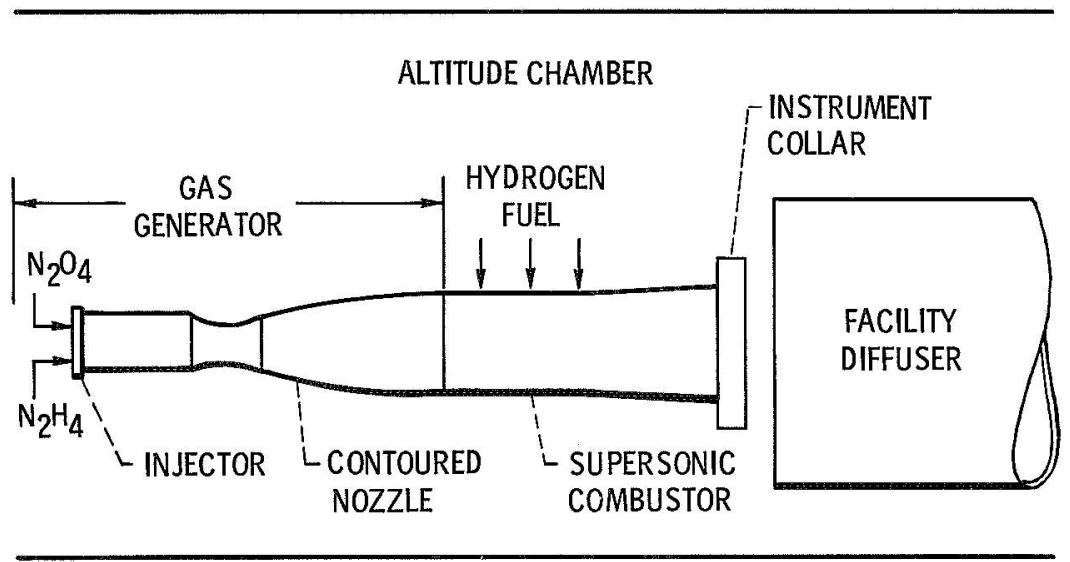

CS -46635

Figure 1. - Schematic of combustor test facility.

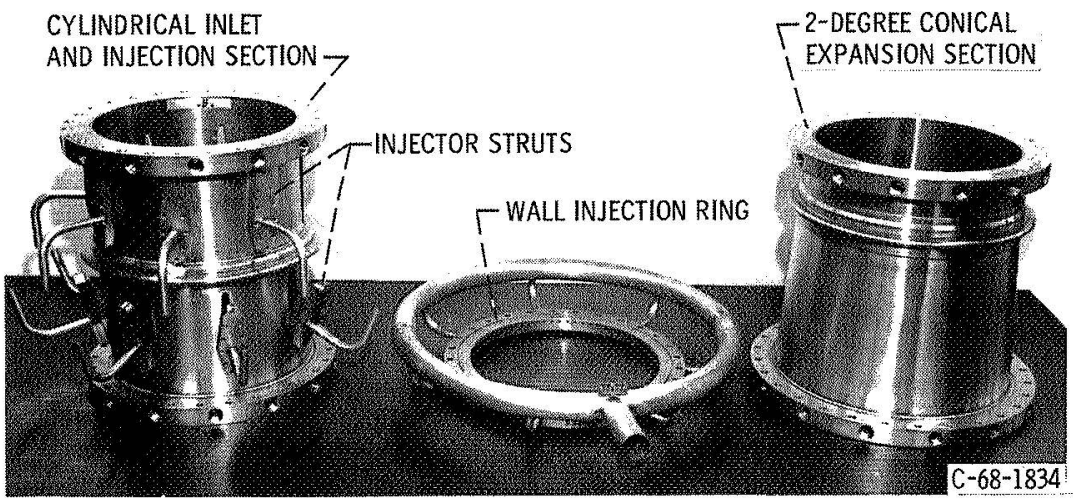

Figure 2. - Disassembled combustor test hardware. 


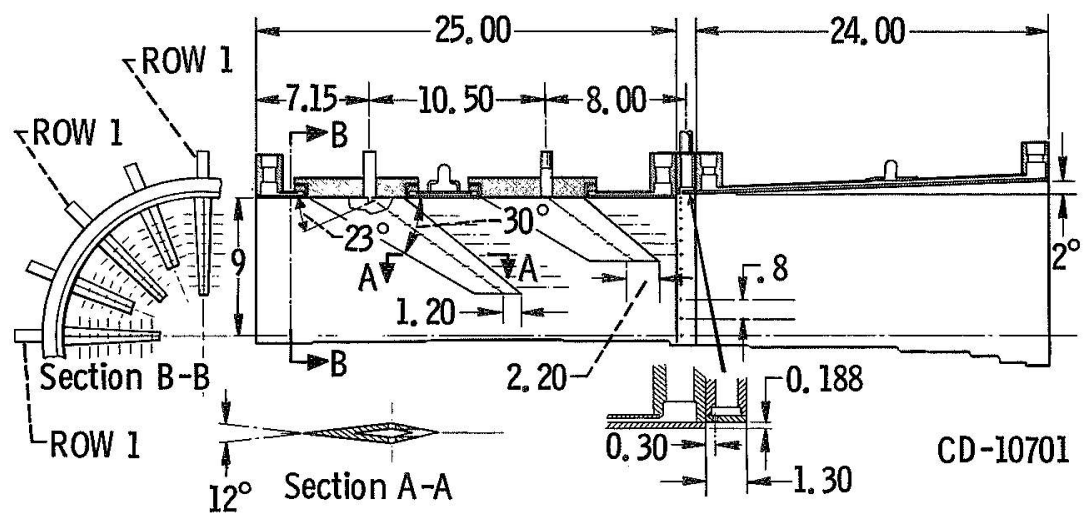

\begin{tabular}{|c|}
\hline INJECTOR DRILLING LOCATIONS \\
DISTANCE FROM WALL-INCHES \\
\\
1.25 \\
1.78 \\
2.36 \\
3.00 \\
3.73 \\
4.46 \\
5.15 \\
5.89 \\
6.66 \\
\hline
\end{tabular}

Figure 3. - Pertinent details of test combustor assembly.

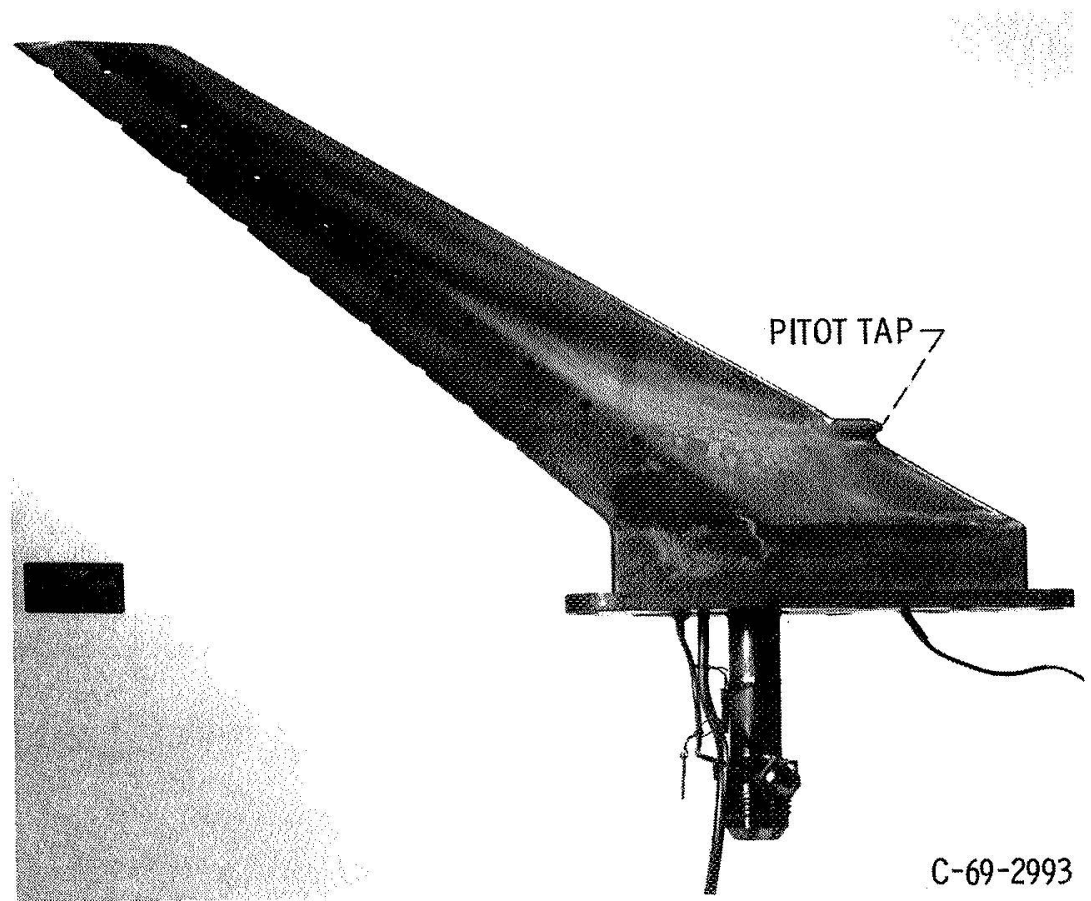

Figure 4. - Hydrogen injector strut - long blade. 
- WALL THERMOCOUPLE LOCATION

- WALL STATIC PRESSURE TAP LOCATION

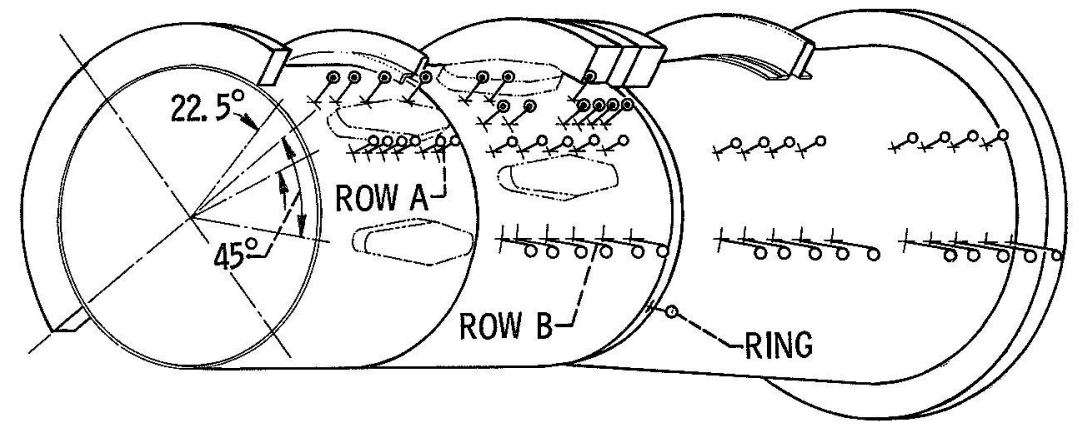

PRESSURE TAP LOCATIONS

\begin{tabular}{|ccc|lc|c|}
\hline \multicolumn{3}{|c|}{ ROW A } & \multicolumn{2}{c|}{ ROW B } & RING \\
\hline $3-$ IN. & 15 & 33 & $13-I N$. & 30 & 25.7-IN. \\
4 & 17 & 35 & 14 & 32 & \\
5 & 19 & 37 & 16 & 34 & \\
8 & 20 & 39 & 18 & 36 & \\
9 & 29 & 41 & 20 & 40.85 & \\
13 & 31 & 43 & 22 & 42 & \\
& & 45 & 28.56 & 44 & \\
& & 47 & & 46 & \\
& & & 48 & \\
\hline
\end{tabular}

Figure 5. - Orientation of hydrogen injectors and combustor wall instrumentation.

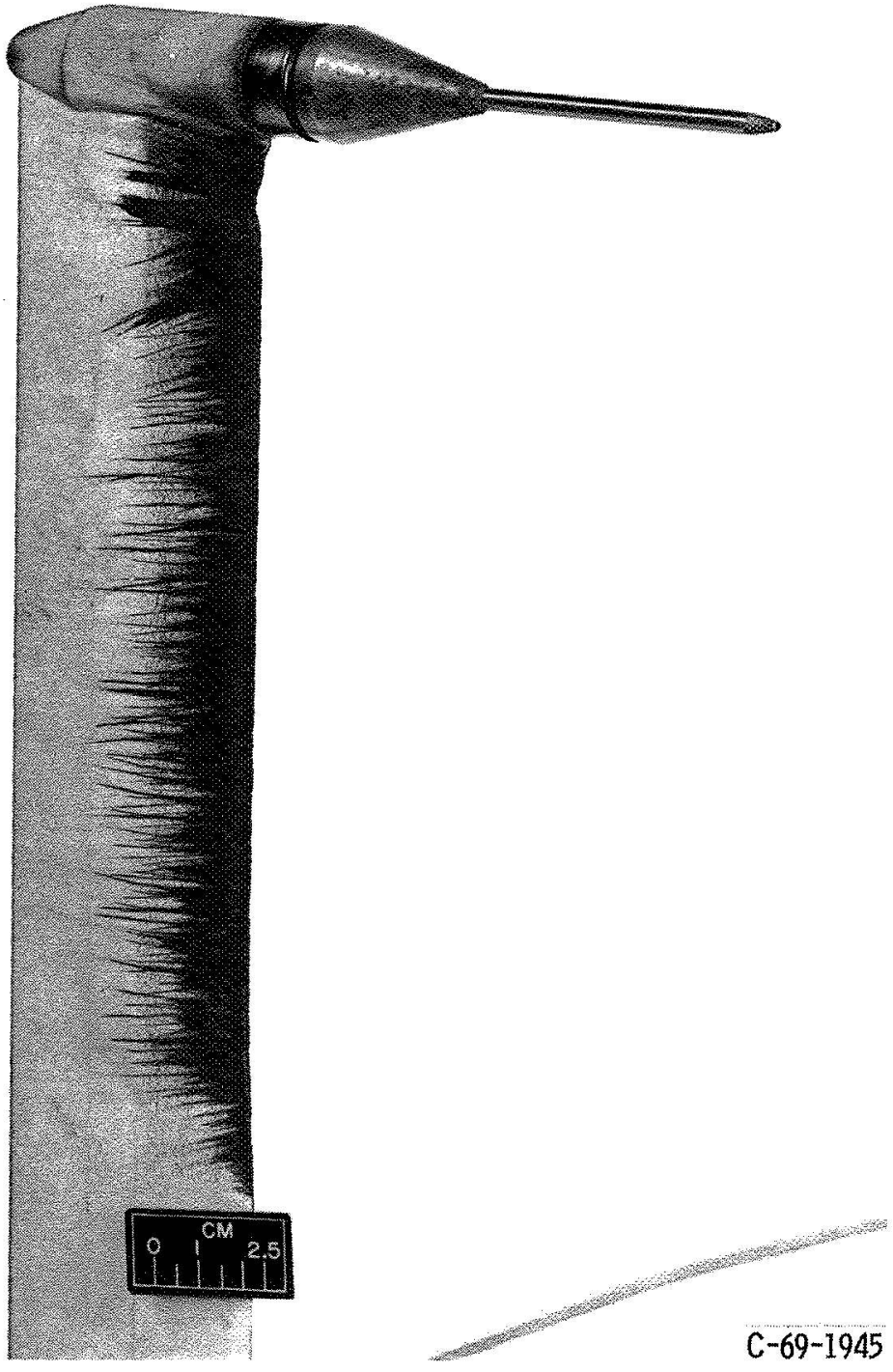

Figure 6. - Stream pitot probe and support strut. 

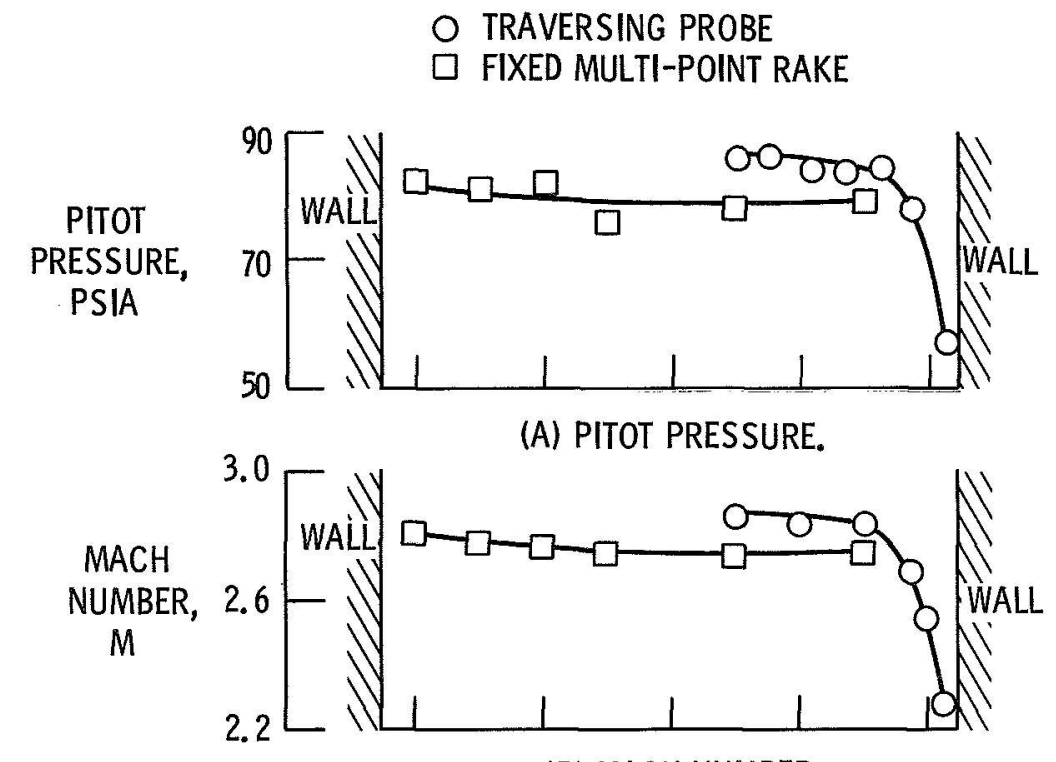

(B) MACH NUMBER.

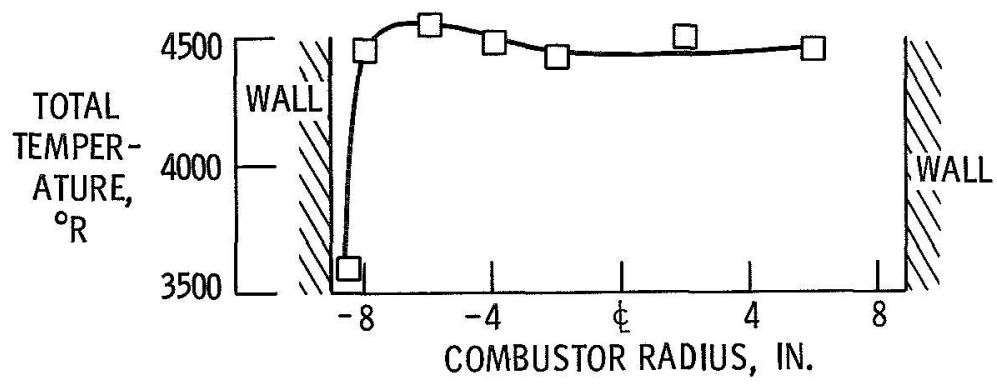

(C) TOTAL TEMPERATURE.

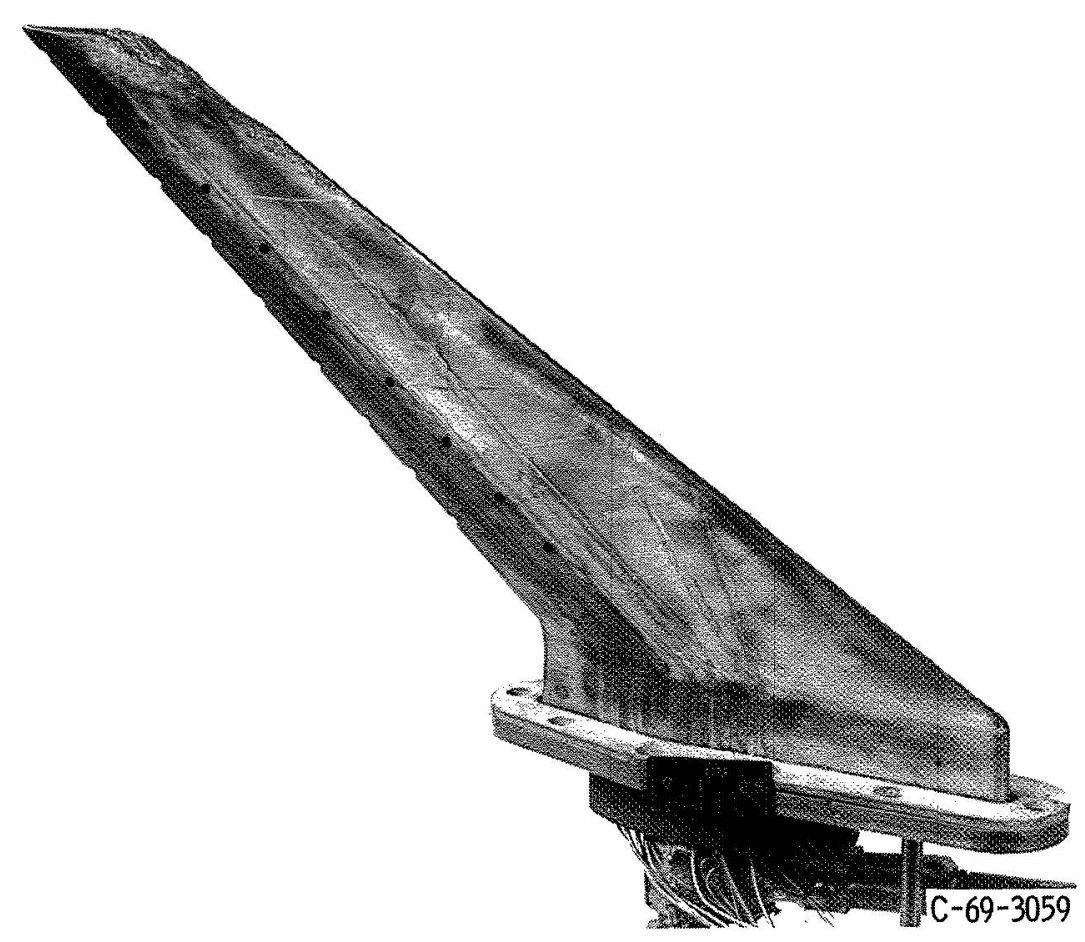

Figure 8. - Heat damaged hydrogen injector strut - Iong blade.

Figure 7. - Measured combustor inlet profiles. $\mathrm{P}_{\mathrm{T}_{2}}=300$ psia, $\mathrm{P}_{\mathrm{S}_{2}}=8.3 \mathrm{psia}$, $\gamma=1.27$. 

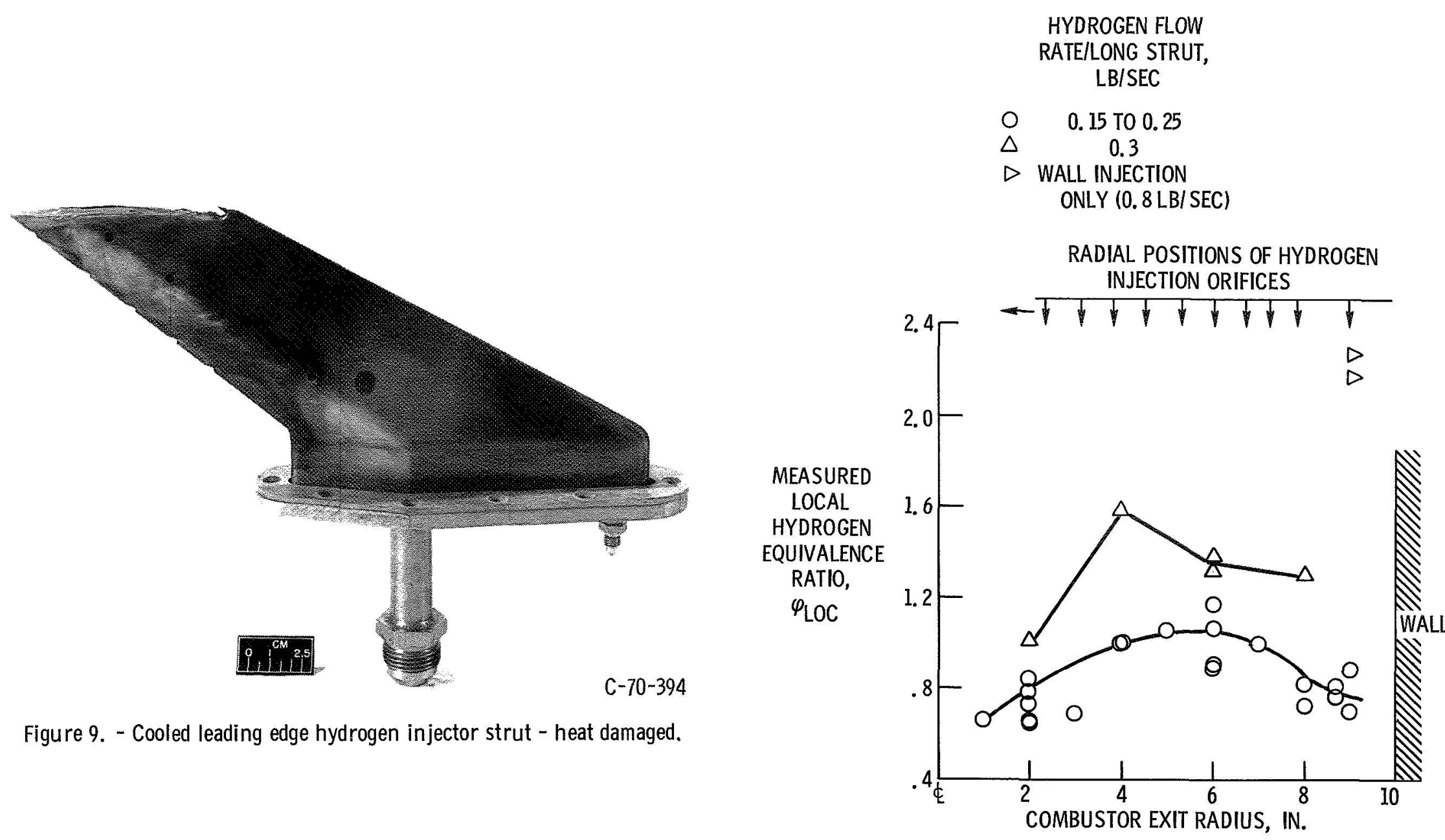

Figure 9. - Cooled leading edge hydrogen injector strut - heat damaged.

Figure 10. - Local hydrogen equivalence ratio in the wake of a long injector strut at the combustor exit. 


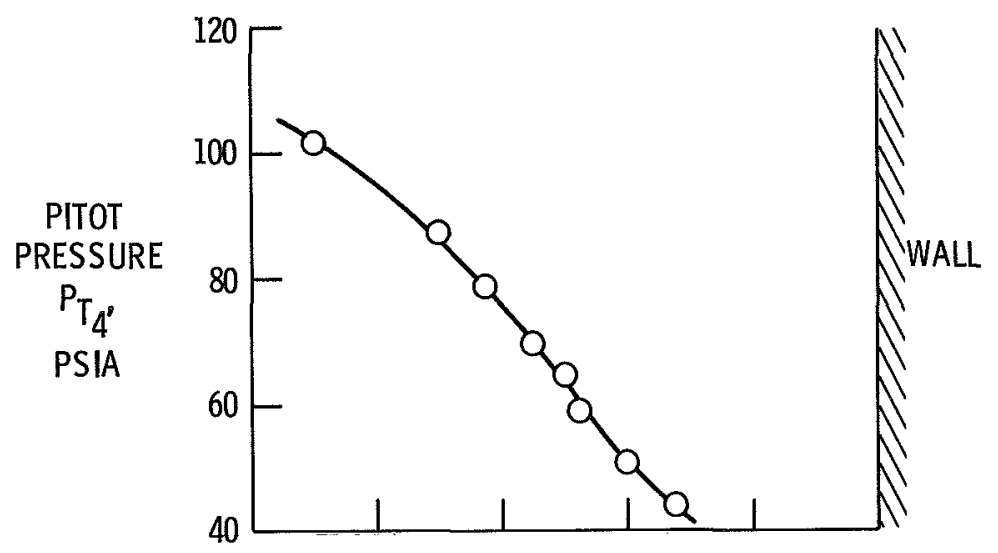

(A) PITOT PRESSURE.

STATIC PRESSURE,

$\mathrm{P}_{\mathrm{S}_{4}}$

PSIA

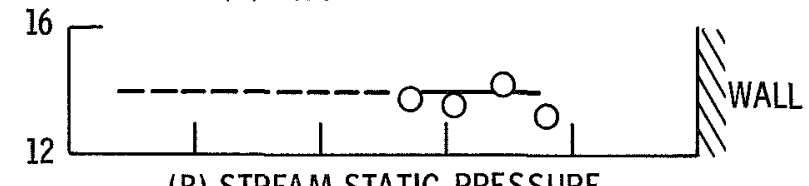

(B) STREAM STATIC PRESSURE.

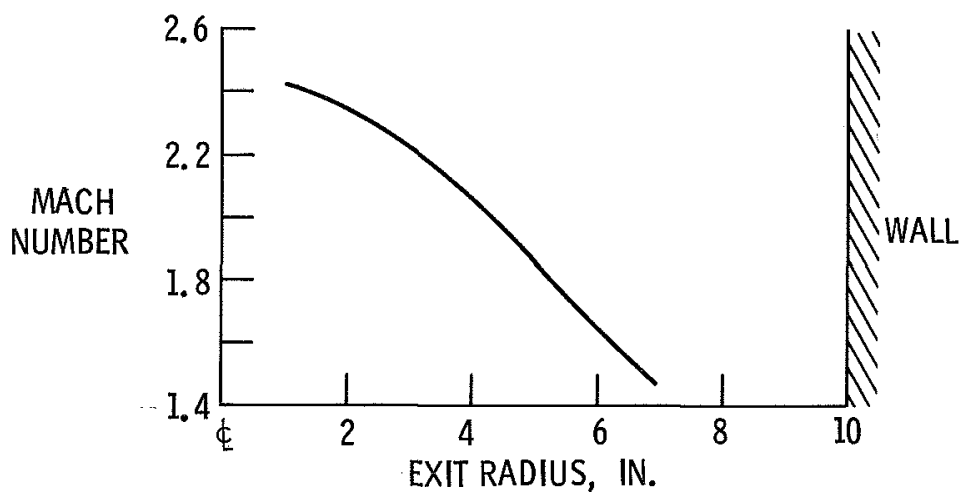

(C) MACH NUMBER.

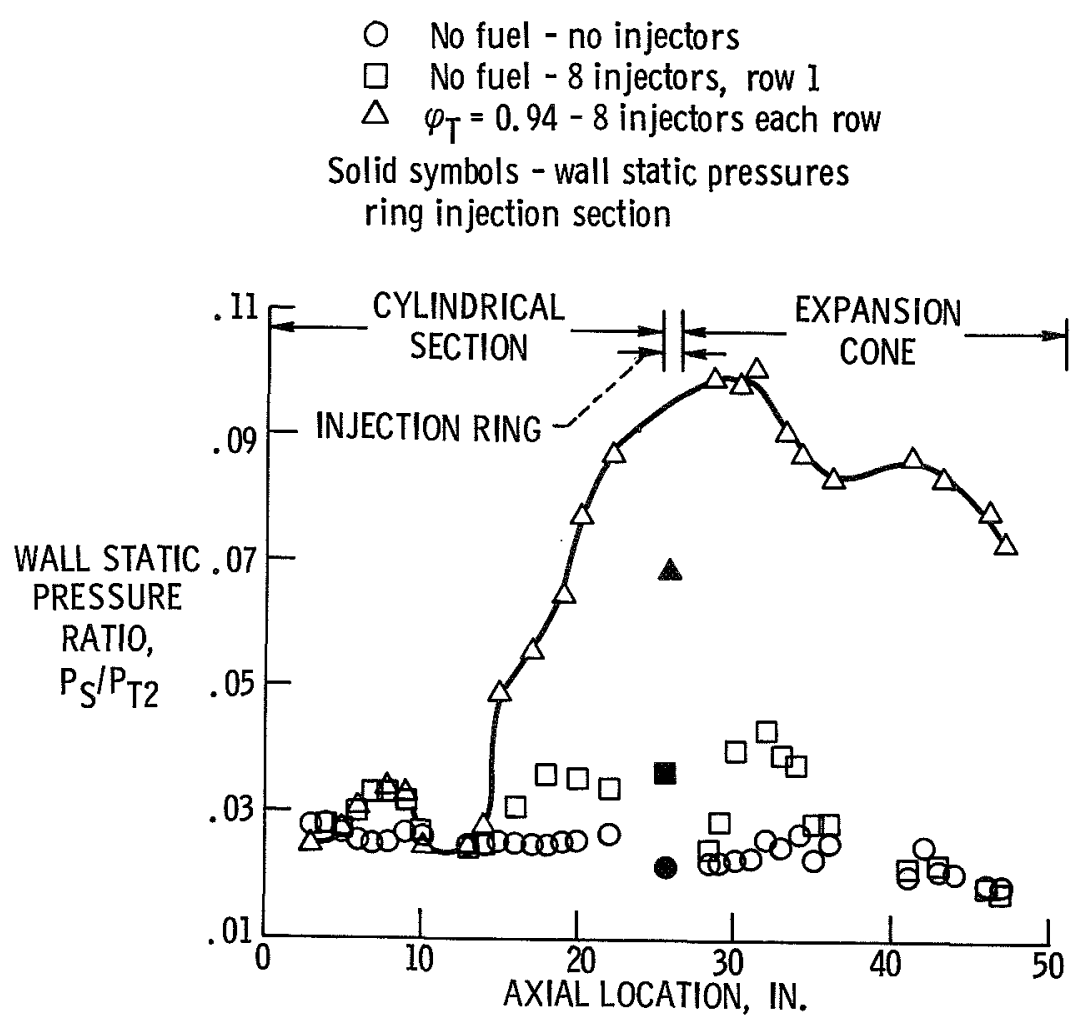

Figure 12. - Combustor wall static pressure distribution. Hydrogen injector flow rate row $1=2.0$; Row $2=0.9$; wall $=0.2 \mathrm{lb} / \mathrm{sec}, \varphi_{\mathrm{T}}=0.94 ; \mathrm{P}_{\mathrm{T} 2}=300 \mathrm{psia}$.

Figure 11. - Combustor exit flow profiles.

$\mathrm{P}_{\mathrm{T}_{2}}=300 \mathrm{psia}, \mathrm{P}_{\mathrm{S}_{2}}=8.3 \mathrm{psia}, \varphi=0.94, \gamma=1.22$. 